\title{
Clima Organizacional no Setor de Hotelaria Hospitalar: um estudo em um hospital privado de João Pessoa, Paraíba (PB), Brasil
}

\author{
Organizational Climate in the Hospital Hotels Sector: a study in a private hospital of \\ João Pessoa, Paraíba (PB), Brasil
}

\author{
Maria Aparecida de Alencar (ALENCAR, M. A. de)* \\ Thales Batista de Lima (LIMA, T. B. de) ${ }^{* *}$
}

\begin{abstract}
RESUMO - Este estudo objetiva analisar o clima organizacional de um hospital privado em João Pessoa, Paraíba (PB), Brasil a partir do olhar de colaboradores do setor de hotelaria hospitalar sobre o seu ambiente de trabalho. A base metodológica trata de uma abordagem quantitativa do tipo descritivo, com aplicação de um questionário a vinte colaboradores. Com os dados tratados, chegou-se aos resultados: o clima organizacional prevalece favorável. Os colaboradores consideraram a organização um bom lugar para trabalhar, há satisfação quanto às condições físicas de trabalho. Foram observados fatores como dedicação, alegria e comprometimento enquanto componentes do ambiente de trabalho. Identificou-se também que o sentir-se acolhido pela empresa é fator de bem-estar. Portanto, conclui-se que os colaboradores se mostram satisfeitos quanto ao ambiente hospitalar. Assim, o estudo contribui para que os gestores realizem constantemente o acompanhamento sobre o clima organizacional, pois a percepção dos respondentes revelou serem volúveis conforme a sensação de seu bem-estar.
\end{abstract}

Palavras-chave: Clima organizacional; Hospital; Hotelaria; Satisfação.

ABSTRACT - This study aims to analyze the organizational climate of a private hospital in João Pessoa, Paraíba (PB), Brazil, from the perspective of employees from the hospitality sector on their work environment. The methodological basis deals with a quantitative approach with descriptive type, and a questionnaire was applied to twenty employees. With the data treated, the following results were reached: the organizational climate is favorable. The employees considered the organization a good place to work and there is satisfaction related to the structural conditions. Factors such as dedication, happiness and commitment were observed as components of the work environment. It was also identified that the feeling of being welcomed by the company is a factor of well-being. Therefore, it was concluded that the employees are satisfied with the hospital environment. Thus, this study contributes to the managers' constant monitoring of the organizational climate, since the perception of the respondents revealed that they can be voluble according to the sensation of their well-being.

Key words: Organizational climate; Hospital; Hospitality; Satisfaction.

\footnotetext{
* Bacharel em Hotelaria pela Universidade Federal da Paraíba (UFPB). Gestora em uma rede hoteleira. Endereço: Universidade Federal da Paraíba/Campus IV, Cidade Universitária, Centro. CEP 58280-000 Mamanguape/PB - Brasil. E-mail: mariaaparecidaalencar220@gmail.com

** Doutorado em Administração (PPGA/UFPB). Docente Adjunto do DCSA/CCAE/UFPB. Endereço: Universidade Federal da Paraíba/Campus IV, Cidade Universitária, Centro. CEP 58280-000 - Mamanguape/PB Brasil. E-mail: thalesufpb@gmail.com

Turismo \& Sociedade (ISSN: 1983-5442). Curitiba, v. 12, n. 1, p. 47-63, janeiro-abril de 2019.
} 


\section{INTRODUÇÃO}

As organizações são compostas por vínculos interpessoais que estruturam o clima organizacional que, por sua vez, determina tanto o comportamento como o desempenho das pessoas que nela envolvem-se. Com o surgimento da sociedade industrial, de acordo com Leão (2012), diversas transformações das bases de organização da vida social foram desencadeadas por processos como a Revolução Industrial inglesa, iniciada a partir de 1760, os processos históricos de expulsão dos trabalhadores do campo, a pilhagem das terras da igreja, o avanço da técnica e o nascimento das fábricas. E essas mudanças foram acompanhadas por diversos problemas sociais, como a degradação das condições de vida e trabalho no séc. XVIII.

Até meados do século $\mathrm{XX}$ as condições precárias do trabalho foram desencadeando estudos que se preocupassem com este cenário, buscando por formas de humanizar mais a administração. Entretanto, as pesquisas eram de caráter geral e indiretamente relacionadas ao tema, como o estudo realizado por Maslow (1954). Somente após a metade do século XX é que essa temática ganhou relevância científico com o propósito de reconhecer suas categorias, componentes e indicadores. Dessa maneira, com a expansão das pesquisas sobre postura do comportamento organizacional, as organizações têm dado maior atenção a essa questão.

O clima organizacional apresenta o estado de contentamento material e emocional dos indivíduos no trabalho, influi no rendimento do cidadão e, por conseguinte da empresa. Por isso é favorável para a empresa e seus colaboradores estimular a motivação, o interesse a boa relação entre os funcionários e a empresa. Para tanto a pesquisa de clima organizacional identifica-se como um conjunto de métodos destinados à investigação e elaboração de estratégias de gestão direcionadas ao melhoramento no clima de trabalho.

Esse estudo busca investigar o clima organizacional em um contexto hospitalar uma vez que ainda são escassas investigações envolvendo esse tema e a hotelaria hospitalar. Sabese que a multidisciplinaridade da área do turismo tem possibilitado novas áreas de atuação profissional, incluindo o setor de saúde. Na hotelaria hospitalar, os conceitos da hotelaria tradicional são adaptados às necessidades das instituições de saúde (MASCARENHAS; SOUZA, 2015). Assim, a hotelaria hospitalar já se tornou uma tendência para aproximar o ambiente do hospital de um hotel, que traz em sua essência de adaptação à nova realidade do mercado, modificando e introduzindo novos processos, serviços e condutas. (TARABOULSI, 2003). 
Para analisar o clima organizacional na hotelaria hospitalar este trabalho se pauta nas dimensões propostas por Bizarria et al. (2016), que são conforto físico, reconhecimento e valorização, a harmonia entre colegas, liderança, satisfação com o trabalho, buscando também investigações nos meios das relações dos direitos e suas responsabilidades como conflitos. Ainda há as dimensões relacionadas à segurança, compartilhamento de valores culturais e organizacionais e a identificação com o trabalho.

Sendo assim, este trabalho tem como objetivo analisar o clima organizacional de um hospital privado em João Pessoa, Paraíba (PB) a partir do olhar de colaboradores do setor de hotelaria hospitalar sobre o seu ambiente de trabalho.

\section{FUNDAMENTAÇÃO TEÓRICA}

\subsection{CLIMA, CULTURA E PESQUISA ORGANIZACIONAL}

Segundo Silva et al. (2015, p. 103), “O clima organizacional está relacionado a qualidade do ambiente percebido na empresa pelos colaboradores, e como o mesmo influencia diretamente no comportamento". Ou seja, de acordo com a doutrina imposta pela empresa, é necessário que se forme uma atmosfera em que o colaborador se sinta bem em realizar suas funções de modo eficaz e eficiente para que o resultado final seja benéfico tanto para a organização quanto para o empregado.

Rocha et al. (2014) argumentam que o clima organizacional afeta toda atmosfera do ambiente de trabalho influenciando o comportamento humano de modo que está diretamente ligado aos resultados finais da empresa. Para Silva e Fonseca (2011) o comportamento dos componentes das organizações influencia e é influenciado pelo clima lá existente.

Medeiros (2011) conclui que o clima organizacional é o estado de espírito da empresa percebido pelos seus funcionários e como envolve o ambiente em que eles estão inseridos é adequado que os mesmos contribuam para melhorar o clima lá percebido. É a partir da identificação cultural de comportamento individual que se pode obter informações sobre a cultura da empresa e de cada um de seus colaboradores e a partir desse conhecimento gerar medidas de motivação que favoreça para um melhor clima organizacional.

Gonçalves Neto (2016) explana que a temática do clima organizacional se vincula a muitas variáveis que influenciam na percepção dos funcionários:

- Liderança: O líder é quem comanda as ações da empresa e quem engaja seus colaboradores a cumprir as metas. 
- Ambiente de Trabalho: O ambiente de trabalho deve fornecer condições favoráveis para o trabalho.

- Salário: Uma remuneração financeira digna do trabalho exercido

- Motivação: Motivar o colaborador de acordo com suas necessidades e capacidades.

Esses pontos devem ser levados em consideração na hora de medir o clima organizacional, e cada um desses pontos tem influência direta no resultado final.

No clima organizacional uma variável relevante é a motivação humana. Para Silva e Fonseca (2011, p. 5) "A motivação se refere ao comportamento que tem como causa as necessidades de indivíduo e tendo como consequência a busca por satisfazer essas necessidades". Gonçalves Neto (2016) aponta que Maslow inclui a teoria das necessidades humanas em forma de pirâmide, na qual é composta por cinco estágios em que são interdependentes. Ou seja, reconhecer e suprir as necessidades essenciais é primordial para a motivação.

Outro autor que abordou a motivação, mais precisamente a motivação no trabalho, foi Frederick Herzberg, que propôs a teoria dos dois fatores que influenciam na motivação. Os fatores são os que causam satisfação e insatisfação. Descobrindo as causas que contribuem para a satisfação ou insatisfação é possível corrigir ou alterar a forma como o encorajamento motivacional no ambiente interno é feito (MARRAS, 2004).

Estudos de motivação desencadearam-se em pesquisas que buscam por uma melhor qualidade de vida no trabalho, de forma que os funcionários se sintam mais satisfeitos em seu ambiente de trabalho. Os níveis de satisfação dos colaboradores podem ser avaliados a partir da pesquisa de clima organizacional. Maia e Sousa (2018) apontam que é fundamental promover uma qualidade de vida no trabalho para aprimorar o desenvolvimento pessoal, a saúde e o bem-estar dos funcionários, requerendo uma atenção por parte dos gestores.

Assim, a motivação contribuiu para o ajuste do clima o organizacional, dela depende o ambiente interno. Ferreira (2011, p. 11) observa que "quando a motivação é baixa, a tendência do clima organizacional é de ser baixo também, demonstrando características de depressão, desinteresse, apatia, insatisfação". Por essa afirmação é possível concluir que quanto mais motivações a empresa empenha em gerar melhor será o clima das organizacional.

Outro aspecto importante no clima organizacional é a liderança. Para Chiavenato (2000, p.107) a "liderança é a influência entre pessoas realizada numa situação e determinada através do processo da comunicação humana para o alcance de um definido objetivo". Nas empresas para que as equipes alcancem seus objetivos é importante uma liderança de excelência. Os fracassos empresariais têm relação com comandos de chefia que segregam o Turismo \& Sociedade (ISSN: 1983-5442). Curitiba, v. 12, n. 1, p. 47-63, janeiro-abril de 2019. 
controle a uma pessoa que está ali somente para exigir cumprimento de metas (CHIAVENATO, 2000). Desse modo, Viana (2018) alega que cabe ao líder ouvir, motivar, ter empatia e conseguir administrar de forma conjunta as equipes.

A liderança influencia no comportamento dos funcionários no ambiente de trabalho, pois, o líder é o indivíduo que inspira por meio do seu exemplo e da sua maneira como lidar com as situações adversas. O líder também é fundamental, pois é ele que planeja e coordena com primazia as ações a serem realizadas durante o processo de produção do produto ou serviço.

O papel do líder nas organizações se assemelha ao cargo de capitão de um navio. Ele é quem comanda o grupo em prol de resultados positivos. Porém, hoje em dia, o líder não somente se limita a comandar, ele deve também ouvir e levar em consideração as opiniões de seus subordinados, para que assim haja harmonia em sua liderança.

Existe uma certa confusão em torno da similaridade entre clima e cultura organizacional, porém, apesar de serem complementares possuem diferenças como aponta Oliveira et al. (2016, p. 198) “A cultura relaciona-se com os valores existentes nas empresas e o clima com o ambiente percebido". Os dois termos estão ligados diretamente, pois de um depende o outro para que os resultados empresariais sejam bem-sucedidos. A cultura organizacional é o conjunto de experiências humanas acumuladas durante muito tempo numa organização. É um sistema coerente de significações (valores, crenças...) e funciona como um "cimento" que une todos os membros em torno dos mesmos objetivos e modos de agir. (HANASHIRO, 2008).

Segundo Gomes (2002), as organizações têm o hábito de admitir pessoas que têm maior facilidade da adaptação a suas regras e cultura, contribuindo para um melhor engajamento profissional e consequentemente colaborando para o favorecimento do clima organizacional. Ademais, a cultura organizacional é importante para a inovação, uma vez que a capacidade de inovar exige um gosto pelo risco e pela vontade de empreender o empreendedorismo, que se fortalece com um clima organizacional e um ambiente de trabalho apropriados que motivam os indivíduos a criar e desenvolver novas ideias (CRUZ; MORALES, 2017).

O ambiente de trabalho é formado por pessoas de hábitos e comportamentos diferentes e para um bom desempenho estratégico da empresa é necessária uma forma de homogeneizar e oferecer um clima que contribua para o bem-estar das equipes organizacionais. De acordo com Medeiros (2011, p. 24) é por meio da "cultura organizacional que se condiciona o clima organizacional, envolvendo a todos com a definição de políticas, costumes, regulamentos". 
Para tanto, é importante o líder partilhar os valores e crenças da organização para assim os colaboradores captarem as missões e objetivos finais e cooperarem com os resultados, fazendo assim com que todos absorvam o mesmo modo de agir e pensar. Quanto mais clareza na explanação das normas da empresa, melhor entendimento há perante os funcionários. Também é importante que cada empresa partilhe sua cultura com os funcionários para que esses possam transmiti-la ao lidarem com os clientes (SOUSA, GARCIA, 2011). Portanto, partilhar da cultura da organização contribui para a adaptação de cada integrante na dinâmica da empresa (SILVA; FONSECA, 2011).

De acordo com Medeiros (2011) existem vários níveis de culturas que devem ser levadas em conta em uma organização, são eles:

- Os artefatos visíveis: São aqueles observados facilmente, tais como decorações, uniformes, quadro de missões, se é um ambiente de formalidades ou informal.

- Valores compartilhados: São os valores que definem porque as pessoas fazem o que fazem;

- Pressuposições básicas: São as crenças e as percepções dominantes das empresas;

- Missões e metas: Como a empresa lida com os problemas, com os objetivos definidos e com o tratamento dos funcionários;

- Símbolos, ritos e cerimoniais: diz respeito à relação dos funcionários de níveis de hierarquia diferente, por exemplo, como os líderes motivam e recompensam os colaboradores;

- A história contada pelas pessoas: A história da fundação da empresa e como é transmitida.

A junção de níveis exposta anteriormente contribui para identificar a natureza da cultura das organizações. Desse modo, diversos elementos que compõe uma organização afetam a cultura e renova o clima organizacional (MAIA; SOUSA, 2018).

Entender o clima organizacional de uma organização consiste em estudar o grau de motivação de seus funcionários e saber as opiniões desse coletivo, e essa pesquisa é um procedimento de administração da organização.

Conforme Luz (2003, p.42) a pesquisa de clima organizacional é "uma ferramenta significativa para oferecer contribuições capazes de melhorar constantemente o ambiente de trabalho". O autor salienta ainda que numa empresa podem ser encontradas pessoas tristonhas, desmotivadas por razões profissionais ou porque elas possuem uma condição familiar ou social distinta. Desta maneira, a empresa pode entender onde seus colaboradores residem, como residem, a renda familiar, como vivem e os problemas encontrados longe do trabalho. 
Para Tachizawa (2001) alguns fundamentos precisam ser questionados numa pesquisa de clima organizacional: entendimento da missão; crença e valores; chefia e liderança; relações interpessoais; salários e benefícios. O autor enfatiza que a avaliação desses fundamentos deve ser visualizada como um importante mecanismo programado para a preparação eficaz das organizações.

Então, a pesquisa de clima organizacional é um dispositivo de avaliação do exemplo de gestão e da política de desenvolvimento organizacional, proporcionando custeios para o setor de marketing da empresa (SIERRA ET AL., 2017). Nesse sentido, Kahale esclarece que:

[...] a mesma se procede a partir da busca das necessidades do clima interno e que seu objetivo é mapear ou retratar os pontos críticos que representam o momento motivacional dos funcionários da empresa por meio do apuramento de seus pontos fortes, deficiências, expectativas e aspirações. (KAHALE, 2003, p. 1).

Tachizawa (2001) estabeleceu uma relação de objetivos para uma pesquisa de clima organizacional: analisar a cultura organizacional da empresa; investigar os ideais que os empregados fazem da empresa, de sua função e de seus objetivos; verificar se existe integração entre os objetivos dos empregados e os objetivos da organização; analisar se existe ligação entre a satisfação na organização e a oferta do composto de benefícios e serviços; medir a dimensão de comprometimento dos empregados com suas encargos e responsabilidades, com clientes e com os agentes internos e externos.

Luz (2012) acentua que a pesquisa de clima distingue tanto questões reais no espaço dos vínculos de trabalho como questões eventuais, propiciando sua precaução por meio do desenvolvimento ou adoção de determinadas ações. O autor certifica que, são necessários instrumentos formais de mapeamento da realidade interna, por intermédio de inventários planejados, conhecidos como pesquisa de clima e de qualidade de vida, que averiguam o ambiente interno e estabelecer em vista disso, o ponto de partida para qualquer recurso de transformação. É necessário compreender como os indivíduos se sentem na organização e como enfrentam aos métodos de mudanças.

Para Bom Sucesso (1998) sem estes diagnósticos, qualquer padrão de mudança encontrará contratempos e será capaz de estar comprometido. Por essa razão antes de definir modelo de mudança numa organização, o andamento fundamental é enxergar como os indivíduos estão se sentindo em ligação a uma sequência de interrogação que dizem respeito às variáveis motivacionais: estratégia e objetivos da empresa; estilo de gerenciamento; salários; benefícios; relações dentro de equipes; sistemas interno de comunicação; interesses e 
expectativas pessoais; relações entre os membros das equipes; características das tarefas; capacidade e estilo das lideranças; condições e recursos de trabalho disponíveis; percepção sobre benefícios e recompensas.

Enfim, Rocha, Ceretta e Lima (2014) comentam que o grande uso de pesquisas de clima organizacional por parte das organizações se deve à abrangência teórica do construto e à capacidade de avaliar características complexas como liderança, reconhecimento, relação interpessoal, recompensa, entre outros, com base nas percepções dos trabalhadores das organizações. Araque, Córdoba e Meriño (2018) complementam que os sistemas de recompensas precisam trazer retornos para a organização a partir da dedicação dos funcionários. Por isso, o clima organizacional se torna vital para que o quadro de empregados se sintam satisfeitos e compartilhem dos objetivos organizacionais.

A compreensão dos elementos que envolvem a pesquisa de clima organizacional, além de entender que o clima organizacional se insere em uma cultura organizacional auxilia no entendimento de que estudiosos buscaram elencar modelos de clima organizacional. Os modelos servem para nortear que aspectos são considerados ao avaliar em uma pesquisa de clima organizacional, visto que, há uma gama de aspectos dentro de uma organização. Quando gestores percebem algum conflito entre funcionários, alguma desmotivação ou baixa produtividade indica que há algo a ser feito de imediato, pois o problema pode não estar em elementos culturais, mas sim em fatores do clima, que são mais sazonais e imediatos (SIERRA ET AL., 2017).

A literatura ressalta uma diversidade de modelos de clima organizacional, com diferentes e diversas dimensões, que tendem alcançar o fenômeno pelo conhecimento dos indivíduos abrangidos com as organizações. Este trabalho seleciona o modelo desenvolvido por Bizarria et al. (2016) por considerar vastos aspectos que envolve os indivíduos nas organizações. O quadro, a seguir, explana cada dimensão e exemplos de estudos que há aporte teórico sobre cada dimensão identificada. 
QUADRO 1 - DIMENSÕES DO CLIMA ORGANIZACIONAL MAIS ATUAL NA LITERATURA

\begin{tabular}{|c|c|c|}
\hline Dimensões & Significado & Exemplos \\
\hline Conforto físico & $\begin{array}{l}\text { Ambiente físico que proporciona conforto e } \\
\text { recursos suficientes para a execução das tarefas e } \\
\text { ambiente confortável. }\end{array}$ & $\begin{array}{l}\text { Litwin e Stringer (1968); } \\
\text { Schneider (1975); Bispo (2006); } \\
\text { Colossi (1991); de Martins et al. } \\
(2004)\end{array}$ \\
\hline $\begin{array}{l}\text { Reconhecimento e } \\
\text { Valorização }\end{array}$ & $\begin{array}{l}\text { Avalia o entendimento quanto ao apropriado } \\
\text { reconhecimento por trabalhos bem produzidos; o } \\
\text { reconhecimento em relação a boa qualidade do } \\
\text { trabalho. }\end{array}$ & $\begin{array}{l}\text { Coda (1997); Rubbo (2002); } \\
\text { Coda (1997) }\end{array}$ \\
\hline $\begin{array}{l}\text { Coesão entre } \\
\text { colegas }\end{array}$ & $\begin{array}{l}\text { Harmonia, ligações e parceria entre parceiros de } \\
\text { trabalho. }\end{array}$ & $\begin{array}{l}\text { Litwin e Stringer (1968); Coda } \\
\text { (1997); de Martins et al. (2004) }\end{array}$ \\
\hline Liderança & $\begin{array}{l}\text { A percepção de que a liderança exercida com } \\
\text { base na competência sendo, portanto, aceita pela } \\
\text { organização e seus membros; comportamento das } \\
\text { chefias; aborda o encorajamento pelo chefe ao } \\
\text { desenvolvimento profissional, feedback claro } \\
\text { sobre assuntos que afetam o trabalho e conversa } \\
\text { franca sobre o desempenho pessoal. }\end{array}$ & Schneider (1975); Coda (1997) \\
\hline $\begin{array}{l}\text { Satisfação com o } \\
\text { trabalho }\end{array}$ & $\begin{array}{l}\text { Analisar os retornos oferecidos pela empresa em } \\
\text { termos de salários e promoção, convívio com os } \\
\text { companheiros e as gestões e o quanto a execução } \\
\text { das tarefas oferecem ao trabalhador sentimentos } \\
\text { satisfatórios ou agradáveis. }\end{array}$ & $\begin{array}{l}\text { Schneider (1975); Colossi } \\
\text { (1991) }\end{array}$ \\
\hline Conflitos & Existência de grupos excluídos ou recolhidos. & $\begin{array}{l}\text { Litwin e Stringer (1968); } \\
\text { Schneider (1975) }\end{array}$ \\
\hline Responsabilidade & $\begin{array}{l}\text { Estágio em que os indivíduos notam que podem } \\
\text { apontar algumas decisões a respeito de sua função } \\
\text { na empresa no objetivo de alcançar o propósito da } \\
\text { organização. }\end{array}$ & $\begin{array}{l}\text { Litwin e Stringer (1968); } \\
\text { Schneider (1975) }\end{array}$ \\
\hline Segurança & $\begin{array}{l}\text { Analisa a sensação de confiança para a pretensão } \\
\text { de riscos ligados ao trabalho e à organização. }\end{array}$ & Rubbo (2002); Bispo (2006) \\
\hline $\begin{array}{l}\text { Cultura } \\
\text { Organizacional }\end{array}$ & $\begin{array}{l}\text { Apresentam os valores organizacionais } \\
\text { (colaboração, ser capaz, disputa, contentamento, } \\
\text { comodidade) e as práticas organizacionais } \\
\text { (adaptação, convívio, gratificação, capacitação). }\end{array}$ & Colossi (1991); Bispo (2006) \\
\hline $\begin{array}{l}\text { Sentidos do } \\
\text { Trabalho }\end{array}$ & $\begin{array}{l}\text { Vivência de agradecimento profissional, } \\
\text { satisfação, reconhecimento com o trabalho que } \\
\text { faz, fortificando a constituição e expressão da } \\
\text { subjetividade. }\end{array}$ & Coda (1997) \\
\hline
\end{tabular}

FONTE: Adaptado de Bizarria et al. (2016)

De acordo com Bizarria et al. (2016), as pesquisas avançam na discussão dos fatores que influenciam o clima organizacional, de forma que os estudos exploram aspectos estruturais e contextuais do trabalho, considerando o reconhecimento e a valorização do trabalhador, tendo o relacionamento interpessoal como um comportamento preponderante, bem como a postura de liderança. Além desses, repercute em um clima organizacional favorável a satisfação do empregado, a não existência de conflitos, a sensação de segurança e a responsabilidade. Por fim, a perspectiva dos sentidos do trabalho e da filosofia da organização, como forma de relacionar cultura organizacional com o clima. 


\section{METODOLOGIA}

A presente pesquisa utilizou uma abordagem quantitativa do tipo descritivo com dados coletados em uma amostra da população dos funcionários de um hospital privado em João Pessoa - Paraíba. A pesquisa é do tipo descritivo, pois descreve cada passo dado pelo pesquisador na realização do estudo e na aplicação das técnicas de pesquisa (SILVA, 2010). Diante disso, o trabalho consiste em analisar o clima organizacional de um hospital privado em João Pessoa, Paraíba (PB) a partir do olhar de colaboradores do setor de hotelaria hospitalar sobre o seu ambiente de trabalho.

Com relação à amostra que, de acordo com Dalfovo, Lana e Silveira (2008, p. 4), “tem como corpo uma fração da população delineada na pesquisa”, ou seja, uma parte do universo da pesquisa (LIMA; GOMES, 2017), aqueles que se dispuseram a participar da pesquisa no período de realização da coleta dos dados. Nesse sentido, no universo e amostra foram aplicados questionários junto ao pessoal do setor de hotelaria hospitalar do referido hospital. Este setor é composto por trinta funcionários e obteve-se a resposta de vinte questionários, compondo dessa forma uma amostra não probabilística. A amostragem não probabilística é "aquela em que a seleção dos elementos da população para compor a amostra depende, ao menos em parte, do julgamento do pesquisador ou do entrevistador no campo." (MATTAR, 2006, p. 271). Salienta-se que alguns funcionários se encontravam de férias ou folga, por isso que não foi possível o universo do setor estudado.

O questionário era composto de doze questões sendo quatro relacionadas ao perfil e oito em relação das dimensões de Bizarria et al. (2016), sendo quatro questões da dimensão de conforto físico, reconhecimento do trabalho em equipe, quatro da dimensão de liderança, responsabilidade e conflitos e quatro da dimensão de segurança, valores culturais e identificação com trabalho. As questões tinham suas respostas baseadas na escala de Likert. Foram entregues trinta questionários a uma profissional do setor de hotelaria hospitalar no dia 10 de setembro de 2018, na qual foi explanado as questões para sanar quaisquer dúvidas e posteriormente na data 14 de setembro de 2018 recolheu-se os vinte questionários que foram respondidos.

Reforça-se que a pesquisa se utilizou da escala de Likert, na qual os respondentes escolhem somente um dos pontos estipulados na escala, em um sistema de cinco categorias de respostas (pontos), partindo do 'muito satisfeito' até 'muito insatisfeito'. Essa escala também introduz o caráter bidimensional com um ponto neutro no meio (DALMORO; VIEIRA, 2013; BARBOSA; LIMA, 2016). 
A análise ocorreu por meio de estatística descritiva na qual aborda-se os percentuais a respeito de cada questão para investigar melhor a percepção desses colaboradores com relação as dimensões propostas por Bizarria et al. (2016), no intuito de averiguar o quanto eles estão satisfeitos ou não com relação ao clima organizacional. Para uma melhor apresentação a análise é ilustrada por meio de quadros que apresentam os percentuais de cada questão, os dados foram trabalhados pelo Excel.

\section{RESULTADOS DAS DIMENSÕES}

Esse estudo tem o intuito de analisar o clima organizacional de um hospital privado em João Pessoa, Paraíba (PB) a partir do olhar de colaboradores do setor de hotelaria hospitalar sobre o seu ambiente de trabalho. Para isso, os vinte respondentes trazem suas percepções em relação a cada dimensão abordada por Bizarria et al. (2016). O modelo deste autor escolhido ocorreu pela abrangência e profundidade que cada dimensão apresenta. Assim, o quadro exposto a seguir revela o grau de satisfação em relação as primeiras dimensões destinadas ao conforto físico e o reconhecimento do trabalho em equipe.

QUADRO 2 - DIMENSÕES: CONFORTO FÍSICO, RECONHECIMENTO DO TRABALHO EM EQUIPE

\begin{tabular}{|c|c|c|c|c|c|}
\hline \multicolumn{6}{|c|}{ DIMENSÕES: Conforto físico e reconhecimento do trabalho em equipe } \\
\hline & $\begin{array}{c}\text { Muito } \\
\text { Insatisfeito }\end{array}$ & Insatisfeito & $\begin{array}{l}\text { Nem Satisfeito } \\
\text { e Nem Insatisfeito }\end{array}$ & Satisfeito & $\begin{array}{l}\text { Muito } \\
\text { Satisfeito }\end{array}$ \\
\hline $\begin{array}{l}\text { Como se sente em relação aos } \\
\text { aspectos: }\end{array}$ & 1 & 2 & 3 & 4 & 5 \\
\hline $\begin{array}{l}1^{a} \text { Conforto e bem-estar físico } \\
\text { no ambiente de trabalho }\end{array}$ & & & $5 \%$ & $50 \%$ & $45 \%$ \\
\hline $\begin{array}{l}2^{\mathrm{a}} \text { Reconhecimento por todos do } \\
\text { meu trabalho. }\end{array}$ & & & $8 \%$ & $55 \%$ & $37 \%$ \\
\hline $3^{\text {a }}$ Equipe de trabalho. & & & $20 \%$ & $30 \%$ & $50 \%$ \\
\hline $4^{\text {a }}$ Trabalho que realiza. & & $1 \%$ & $12 \%$ & $13 \%$ & $75 \%$ \\
\hline
\end{tabular}

Fonte: Dados da pesquisa (2019)

Em relação ao conforto físico e o reconhecimento do trabalho em equipe, por meio do Quadro 2 se observa um nível de satisfação igual ou superor a $80 \%$ em todos os aspectos - o conforto e bem-estar físico, reconhecimento do seu trabalho, satisfação com a equipe e a realização do trabalho. $\mathrm{O}$ aspecto em que a satisfação é menor em relação aos demais é em relação à equipe de trabalho. 
Rocha, Ceretta e Lima (2014) atentam que o reconhecimento pelo esforço desempenhado pelo funcionário é fundamental para garantir a motivação dele que resulta em benefícios contínuos para a organização, bem como para o próprio funcionário. $\mathrm{E}$ tal reconhecimento, por vezes, ocorre pela equipe de trabalho. Assim, é bom que o hospital se atente melhor às atividades de suas equipes, pois saber as necessidades da equipe é de responsabilidade dos gestores. Estes contribuem significativamente na maneira de atuação dos integrantes de uma equipe (CHIAVENATO, 2000).

Enquanto as primeiras dimensões dizem respeito aos aspectos estruturais e de relacionamento entre colegas, o próximo quadro apresenta dimensões relacionada à liderança, responsabilidade e conflitos. Isto é, são dimensões direcionadas ao engajamento, comprometimento e gerenciamento de conflitos dentro do âmbito da organização.

QUADRO 3 - DIMENSÕES: LIDERANÇA, RESPONSABILIDADE E CONFLITOS

\begin{tabular}{|c|c|c|c|c|c|}
\hline \multicolumn{6}{|c|}{ DIMENSÕES: Liderança, responsabilidade e conflitos } \\
\hline & $\begin{array}{c}\text { Muito } \\
\text { Insatisfeito }\end{array}$ & Insatisfeito & $\begin{array}{l}\text { Nem Satisfeito } \\
\text { e Nem Insatisfeito }\end{array}$ & Satisfeito & $\begin{array}{c}\text { Muito } \\
\text { Satisfeito }\end{array}$ \\
\hline $\begin{array}{l}\text { Como se sente em relação aos } \\
\text { aspectos: }\end{array}$ & 1 & 2 & 3 & 4 & 5 \\
\hline $5^{\text {a }}$ Execução de tarefa. & & $1 \%$ & $10 \%$ & $70 \%$ & $19 \%$ \\
\hline $6^{\mathrm{a}}$ Comunicação com superiores. & & $3 \%$ & $5 \%$ & $12 \%$ & $80 \%$ \\
\hline $\begin{array}{l}7^{\mathrm{a}} \text { Grau das instruções passadas } \\
\text { pelo meu líder. }\end{array}$ & & $2 \%$ & $5 \%$ & $12 \%$ & $80 \%$ \\
\hline $\begin{array}{l}8^{\text {a }} \text { Conflitos internos dentro da } \\
\text { empresa. }\end{array}$ & & $95 \%$ & $5 \%$ & & \\
\hline
\end{tabular}

Fonte: Dados da pesquisa (2019).

Em relação no Quadro 3 percebe-se que há uma satisfação superior a $90 \%$ de satisfação em todas as questões - execução de tarefa, comunicação com meus superiores, grau das instruções passadas pelo meu líder, conflitos internos dentro da empresa. Conforme Sousa e Garcia (2011), a liderança é uma peça importante no emaranhado organizacional e, por meio dela, é possível desenvolver ações em prol do desenvolvimento profissional e organizacional com base na busca de realização de tarefas, com aporte na extensão do relacionamento estabelecido, diante das demandas do ambiente que são mais bem administradas se o líder em questão tiver habilidade em adaptar seu estilo ao contexto situacional. As ferramentas de gestão quando bem executadas ajudam os colaboradores a se desenvolverem como líderes (SILVA; EVANGELISTA; BERNARDO, 2015). 
Observa-se com maior porcentagem, que a principal preocupação dos colaboradores busca encontrar uma forma de trabalhar com a sensação de bem-estar na sua carreira. Isso corrobora com o argumento de Maia e Sousa (2018) com relação à promoção da qualidade de vida no trabalho, pois propicia bem-estar no ambiente de trabalho. Quando o indivíduo se sente bem acolhido passa a se identificar mais com seu trabalho, criando um vínculo de pertença por considerar seguro o seu trabalho. Por isso, o Quadro 4 trata das dimensões de segurança, valores culturais e identidade com o trabalho.

QUADRO 4 - DIMENSÕES: SEGURANÇA, VALORES CULTURAIS E IDENTIFICAÇÃO COM O TRABALHO

\begin{tabular}{|c|c|c|c|c|c|}
\hline \multicolumn{6}{|c|}{ DIMENSÕES: Segurança, valores culturais e identificação com o trabalho } \\
\hline \multirow{2}{*}{$\begin{array}{l}\text { Como se sente em relação aos } \\
\text { aspectos: }\end{array}$} & $\begin{array}{c}\text { Muito } \\
\text { Insatisfeito }\end{array}$ & Insatisfeito & $\begin{array}{l}\text { Nem Satisfeito } \\
\text { e Nem Insatisfeito }\end{array}$ & Satisfeito & $\begin{array}{c}\text { Muito } \\
\text { Satisfeito }\end{array}$ \\
\hline & 1 & 2 & 3 & 4 & 5 \\
\hline $\begin{array}{l}9^{a} \text { Responsabilidades a mim } \\
\text { atribuídas. }\end{array}$ & $1 \%$ & $1 \%$ & $10 \%$ & $23 \%$ & $65 \%$ \\
\hline $\begin{array}{l}10^{a} \text { Segurança que é oferecida no } \\
\text { ambiente de trabalho. }\end{array}$ & & $2 \%$ & $22 \%$ & $56 \%$ & $20 \%$ \\
\hline $\begin{array}{l}11^{\mathrm{a}} \text { Área que estou atuando } \\
\text { atualmente. }\end{array}$ & & & $10 \%$ & $25 \%$ & $65 \%$ \\
\hline $\begin{array}{l}12^{\text {a }} \text { Cultura organizacional } \\
\text { complexa e suas expectativas de } \\
\text { crescimento dentro da empresa. }\end{array}$ & & & $34 \%$ & $37 \%$ & $29 \%$ \\
\hline
\end{tabular}

FONTE: Dados da pesquisa (2019).

De acordo com dados apresentados no Quadro 4 todas as questões - responsabilidade, segurança no ambiente de trabalho, área de atuação e cultura organizacional e expectativas de crescimento dentro da empresa - há uma satisfação superior a $65 \%$.

Os resultados ratificam o entendimento de Hanashiro (2008) acerca da cultura organizacional como forma de unir as pessoas e desenvolver o espírito de coletividade dentro da organização. Se os respondentes avaliaram bem tais dimensões significa que o referido hospital desenvolveu uma cultura organizacional consistente por meio de valores que seus funcionários defendem e ajuda a mantê-los unidos, apenas necessitando de um maior reconhecimento, conforme já foi apontado.

Vale destacar que o resultado satisfatório nestas dimensões reflete no quanto a cultura organizacional desempenha a função de entender a vida organizacional, contribuindo na construção de um ambiente mais seguro e confortável aos funcionários, culminando em um bom clima organizacional (SILVA; FERNANDES, 2019). Frisa-se o argumento de Bustamante-Ubilla, Avendaño e Maza (2015) quando afirmam que em âmbito hospitalar é 
imprescindível que sejam oferecidos espaços de colaboração abertos por meio de uma comunicação fluída para um trabalho eficiente entre gestores e funcionários, uma vez que estes devem propiciar um serviço de saúde de qualidade à comunidade por meio do calor humano.

Com relação ao clima organizacional percebe-se que os funcionários a partir dos resultados se encontram satisfeitos nas dimensões com o conforto e bem-estar físico, pelo seu trabalho porque é reconhecido por todos, com a execução de tarefa, com a segurança que é oferecida no ambiente de trabalho e com a cultura organizacional complexa e suas expectativas de crescimento dentro da empresa. Porém, eles sentem insatisfeitos na dimensão em relação aos conflitos internos dentro da empresa porque o hospital precisa olhar com mais atenção para esse fator. Assim, para que o colaborador se sinta bem no ambiente de trabalho é necessário que a empresa trabalhe com motivação, procedimentos e os métodos de melhoria do clima organizacional.

\section{CONSIDERAÇÕES FINAIS}

A pesquisa teve como proposta realizar uma análise do clima organizacional de um hospital privado em João Pessoa - Paraíba, utilizando principalmente as dimensões propostas pelos estudos de Bizarria et al. (2016), nas dimensões de conforto físico, reconhecimento e valorização, a harmonia entre colegas, liderança, satisfação com o trabalho, conflitos, responsabilidade, segurança, cultura. Buscou-se também investigações nos meios das relações dos direitos e suas responsabilidades como conflitos e também além as dimensões relacionadas a segurança, compartilhamento de valores culturais e organizacionais e a identificação com o trabalho.

A avaliação dos dados confirma um relacionamento entre as variáveis analisadas e o clima organizacional. Sendo assim, o trabalho revela que há um nível de satisfação positivo a partir da percepção dos respondentes. Porém, no tocante à equipe de trabalho e reconhecimento, foram dimensões que podem ser mais trabalhadas pelos gestores para que os funcionários se sintam mais reconhecidos diante de seus trabalhos desempenhados.

Para isso, faz-se necessário que também se invista na aprendizagem organizacional no sentido de aprenderem a compartilhar conhecimento, tornando a equipe mais coesa e unida. $\mathrm{O}$ estudo de Reyes e Zapata (2014) destacam justamente a alta relação entre um comportamento do indivíduo em compartilhar conhecimento com o clima organizacional. Ou seja, o clima 
melhora entre os funcionários quando aprendem a se ajudar por meio do compartilhamento de conhecimentos adquiridos.

Dessa forma é preciso que os colaboradores tomem consciência de seus papéis e estabeleçam objetivos e metas profissionais para evitar frustrações quando estiverem inseridos na hotelaria hospitalar. Por fim, a pesquisa teve como limitação a falta de alcance dos demais funcionários do setor da hotelaria hospitalar do hospital. Também teve como limitação a dificuldade de achados em estudos que se pautassem na aplicação de algum modelo específico de clima organizacional desenvolvido por algum autor, sobretudo, no campo da hotelaria hospitalar.

A política de clima organizacional é relevante para o bem-estar dos colaboradores e outros estudos poderiam ampliar para os demais setores do hospital, além da hotelaria hospitalar, cuja finalidade é perceber melhor como os funcionários se sentem no seu ambiente de trabalho. Os futuros estudos podem ainda analisar outras políticas de recursos humanos para averiguar o quanto contribuem para o desenvolvimento dos funcionários no setor de hotelaria hospitalar. Enfim, pode ser investigado o clima organizacional a partir também de diferentes modelos, até mesmo para comparar com o modelo utilizado de Bizarria et al. (2016). Portanto, espera-se que futuras pesquisas se apropriem do tema, auxiliando a gestão dos hospitais a conhecerem melhor o seu funcionamento a partir da percepção de seus colaboradores.

\section{REFERÊNCIAS}

CHIRINOS ARAQUE, Y.; MERIÑO CÓRDOBA, V. H.; MARTÍNEZ DE MERIÑO, C. El clima organizacional en el emprendimiento sostenible. Revista Escuela de Administración de Negocios, n. 84, 2018.

BARBOSA, R. G.; LIMA, T. B. Qualidade de Vida no Trabalho em um hotel. Revista Turismo e Desenvolvimento. v. 15, n. 2, 2016.

BIZARRIA, F. P. A.; MOREIRA, A. Z.; MOREIRA, M. Z.; LIMA, A. O. Estudo do clima Organizacional no Setor Industrial. Revista Pensamento Contemporâneo em Administração. Rio de Janeiro, v. 10, n 4, p.80-98, 2016.

BOM SUCESSO, E. P. Trabalho e qualidade de vida. Rio de Janeiro: Qualitymark, 1998.

BUSTAMANTE-UBILlA, M. A.; AVENDAÑO, M. L. G.; MAZA, M. C. L. Caracterización del clima organizacional en hospitales de alta complejidad en Chile. Estudios Gerenciales. v. 31, n. 1, p.432-440, 2015. 
CHIAVENATO, I. Introdução à Teoria Geral da Administração. Ed. Compacta. $2^{\mathrm{a}}$ ed. Rio de Janeiro: Campus, 2000.

CRUZ, Y. M. F.; MORALES, O. L. A. Proposal of an organizational culture model for innovation. Cuadernos de Administración, v. 33, n. 59, p.22-31, 2017.

DALFOVO, M. S.; LANA, R. A.; SILVEIRA, A. Métodos quantitativos e qualitativos: um resgate teórico. Revista Interdisciplinar Científica Aplicada, v. 2, n. 4, p. 1-13, 2008.

DALMORO, M.; VEIRA, K. M. Dilemas na construção de escalas tipo Likert: o número de itens e a disposição influenciam nos resultados? RGO - Revista Gestão Organizacional, v. 6, edição especial, p.161-174, 2013.

FLEURY, A.; FLEURY, M. T. Estratégias empresariais e formação de competências. São Paulo: Atlas, 2000.

GOMES, F. R. Clima Organizacional: um estudo em uma empresa de telecomunicações. RAE. v. 42, n. 2, p.1-9, 2002.

GONÇALVES NETO, J. M. Clima organizacional e turismo: Um estudo de pesquisas em organizações de turismo. X Fórum Internacional de Turismo do Iguassu. Foz do Iguaçu, Paraná, 2016.

HANASHIRO, D. M. M. Convivendo com a diversidade cultural. In: GODOY. A. S. Gestão do fator humano: uma visão baseada em stakeholders. 2. ed. São Paulo: Saraiva, 2008.

KAHALE, F. Pesquisando a Motivação: A Pesquisa de Clima Organizacional. Instituto MVC. 2003.

LEÃO, L. H. C. Psicologia do trabalho: aspectos históricos, abordagens e desafios atuais. Ecos. v. 2, n. 2, p.291-305, 2012.

LIMA, T. B.; GOMES, S. L. Os estilos de liderança na gestão hoteleira: um estudo em hotéis da orla de João Pessoa (PB). Organizações em contexto, São Bernardo do Campo, v. 13, n. 26, p. 19-71, 2017.

LUZ, R. S. Gestão do clima organizacional. Rio de Janeiro: Editora Qualitymark, 2012.

MAIA, A. K. N.; SOUSA, G. H. B. Qualidade de vida no trabalho: uma investigação em unidades da rede hoteleira na cidade de Mossoró, Rio Grande do Norte/RN, Brasil. Revista Turismo e Sociedade. v. 11, n. 1, p.128-146, 2018.

MASCARENHAS, R. G. T.; SOUZA, J. T. A qualidade percebida pelo paciente através dos serviços da hotelaria hospitalar: um estudo sobre a hospitalidade na área da saúde. Revista Turismo e Sociedade, n. 8, n. 3, p.419-445, 2015.

MASLOW, A. H. Motivation and personality. New York: Harper, 1954. 
MEDEIROS, M. Clima organizacional: A influência do clima organizacional na produtividade. Trabalho de Conclusão de Curso. 44 f. Universidade Cândido Mendes. Rio de janeiro, 2011.

REYES, M. M. V.; ZAPATA, D. I. C. Relation Between Organizational Climate and its Dimensions and Knowledge-sharing Behavior among Knowledge Workers. International Journal of Psychological Research. v. 7, n. 2, p.64-75, 2014.

ROCHA, A. C.; CERETTA, G. F.; LIMA, J. A. Clima Organizacional em hospital: um estudo no sudoeste do Paraná. Reuna. v. 19, n. 2, p.71-90, 2014.

SIERRA, J. V. C.; MARCHIANO, M.; BANZATO, C. R.; JUNIOR RABECHINI, R. Fatores de clima organizacional relevantes para a criatividade: estudo de caso em empresas brasileiras. Revista Ciências Administrativas. Fortaleza, v. 23, n. 1, p.217-244, 2017.

SILVA, A. C. R. da. Metodologia da pesquisa aplicada à contabilidade: orientações de estudos, projetos, artigos, relatórios, monografias, dissertações, teses. 3. ed. São Paulo: Atlas, 2010 .

SILVA, V. S.; FONSECA, G. A. A qualidade do clima organizacional como fator contributivo para a motivação e a satisfação no trabalho: um estudo de caso dos profissionais técnicos administrativos da Fundação Visconde de Cairu. Cairu em Revista - Sociedade, Educação, Gestão e Sustentabilidade. v. 1, n. 0, p.1-27, 2011.

SILVA, P. E.; EVANGELISTA, M. A. V.; BERNARDO, M. B. S. R. Clima Organizacional em meios de hospedagem: estudo de caso. Estudos, Goiânia, v. 42, n. 1, p.103-123, 2015.

SILVA, E. N. O.; FERNANDES, J. H. M. A influência do clima organizacional no desempenho das organizações: estudo aplicado em duas empresas no município de Capanema/PA. Trabalho de Conclusão de Curso. 62 f. Universidade Federal Rural da Amazônia. Capanema/PA, 2019.

SOUSA, J. S.; GARCIA, F. C. Clima Organizacional: um estudo de caso em uma rede de farmácias no interior de Minas Gerais. Gestão e Regionalidade. v. 27, n. 79, p.22-31, 2011.

TACHIZAWA, T. Gestão com pessoas: uma abordagem aplicada às estratégias de negócios. 2. ed. Rio de Janeiro: Editora FGV, 2001.

TARABOULSI, F. A. Administração de Hotelaria Hospitalar. São Paulo: Atlas, 2003.

Recebido em: 08-04-2019

Aprovado em: 07-07-2019

Versão aprovada para publicação em: 11-08-2019 